\title{
MyAvis and Converge Applications a better Meter- Management System for the Albanian Power Distribution System (OSHEE)
}

\author{
Anni Dasho ${ }^{1}$, Genci Sharko ${ }^{2}$
}

\begin{abstract}
The main Sales and Distribution Divisions of OSHEEAlbanian Power Distribution Corporate (former CEZ Shpërndarje) were on continuous discussions at CEZ management time and even now when OSHEE is under Albania Government administration and management:
\end{abstract}

- How important, and what will be the impact of developing and implementing an electronic meter reading system (MyAvis \& Converge) to facilitate the work of the readers and transmitting data online through Albanian mobile operators?

- Necessity of continuing with electronic readings, data transmitted online to billing system and online photos of real status of electrometers during reading process?

The two main processes to be managed through Data Cleaning project in close cooperation with management of Loses and Customers Care Application for clarifying and supporting all clients for their problematic cases regarding:

- Management of Common Areas-solution to be implemented in Billing System: close cooperation with management of loses through data cleaning process.

\footnotetext{
${ }^{1}$ Department of Information Technology, Maths and Statistics, Faculty of Economic and Information Technology, European University of Tirana. Blv.Gj.Fishta, Tirana, Albania. (e-mail: anidasho@gmail.com, anni.dasho@uet.edu.al)

${ }^{2}$ Department of Automation, Faculty of Electrical Engineering, Polytechnic University of Tirana, Sheshi Nene Tereza, Tirana, Albania. (e-mail: genci.sharko@lme.upt.al)
}

- Invoice delivery and monthly payment collection through Meter-Readers.

Keywords: MobiRead(MyAvis)\&Converge, monthly electricity bills, electrometers, monthly photos, etc...

\section{Introduction}

Government of Albania is owning through state administration and management the OSHEE -Albanian Distribution System Operator, who has been administered (March 2009- end of February 2013) by CEZ Group which started to meet growing customer expectations by:

- Improving Electricity Quality supplying and Quality Service to Albanian clients

Some of the CEZ Group information systems which have been re-engineered and developed that time and functioning as well even now for OSHEE Company are:

- "MyAvis \& Converge" system for reading clients consumption by readers and on-line reading for Big Clients.

- $\quad$ Centralized Billing System

- Data Cleaning Project in closed cooperation with the Management of Looses Project

In the energy sector one of the successful and innovative project by CEZ Shpërndarje was implementation of an integrated Meter-Management System. By this project the CEZ Group has increased the quality and accuracy of the reading and online integration with Billing System [1], [2], [3]. The project consisted of three main parts.

- Converge system application

This is an Open Access article distributed in accordance with the Creative Commons Attribution Non Commercial (CC-BY-NC-ND 4.0) license, which permits others to copy or share the article, provided original work is properly cited and that this is not done for commercial purposes. Users may not remix, transform, or build upon the material and may not distribute the modified material (http://creativecommons.org/licenses/by-nc/4.0/) 


\section{A. Dasho, G. Sharko \\ MyAvis and Converge Applications a better Meter-Management System for the

(Online reading of about 3000 electricity smart meters for big customers)

- MyAvis system application

(Online reading, through electronic reading devices-PDA's used by the readers)

- Online transmission in both systems was done by using the GPRS network of mobile companies AMC and Vodafone mobile operators.

The previous reading electricity meters system was carried out manually in paper notes records kept by readers for CEZ Shpërndarje/OSHEE customers, and all those data were enter manually through Billing operators at Billing System. This process increase risk of having data redundancy, inaccuracy, insecurity and data entry human error, also unnecessary overload and additional work flow for the CEZ employees. The 2 main projects brough a new challenge for meter management system are:

- Invoice delivery process done by meter readers in cooperation with Billing and MyAvis Systems.

- Management of Common Areas consumption to be treated properly through data cleaning process.

\section{MyAvis(MobiRead) as a real-time meter reading system.}

Analysis, implementation, operation accurate information of a real-time meter reading system has been installed by CEZ Shpërndarje. PDA readers has brought a lot of advanced that most corporate have invested for the implementation of these devices in information technology system for recording and data transmission.

The real-time meter reading system is implementation through PDA devices. This system made possible real-time data transmission of meters reading to data center using the GPRS network provided by Albanian cellular companies. At the data center the MyAvis application interface collect all the data been transmitted from the PDA in the different sites and proceeded to the sales system for further for automatic customer billing calculation and reports. Monthly customer bill is creating by the sales system for each customer in automatic way. System implementation has drastically decrease operations costs and rapidly increased the data transmission flow, meters reading data accuracy and data reliability. System has completely decommissioned the record notes taken by reader manually and eliminated data entry errors in the billing system by the sales operators during the meters reading data entry to the billing system. The system has implemented new features, also, like the ability to take photo of the energy reader meters and send them to the data center for further investigation in case of energy fraud, anomalies or miss reading by the CEZ Shpërndarje personnel increasing the transparency of the company toward the customers and employees towards the company [1], [2], [9].

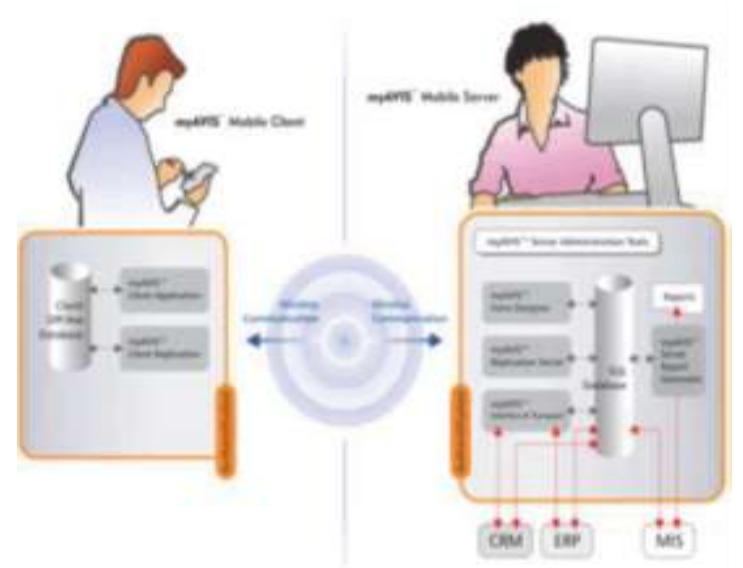

Fig 1. MyAvis System facilitating reading data from Electrometers to the MyAvis and Billing System.

\section{Converge System: Automatic Meter Reading System- flexibility and efficiency from Metering to Billing Systems.}

Converge is an automatic meter reading system, one of the CEZ Group corporate solutions implemented on the region, and in Albania as well, where the Converge system delivers the prerequisites for an automated, endto-end process - from metering to billing. The system utilizes the latest software technology, it can be configured as a standalone or multi-user system, its scalability and modular design provide the prerequisites for a solution that is specifically tailored to CEZ Shpërndarje needs.

CEZ Shpërndarje has invested in terms of automatic reading of customer's data is a new type of energy meter which are electronic smart meter. That equipment makes possible periodically data meter readings and automatically sent periodically to the data center via modem through GPRS system. All these data are proceeded automatically through respective interface to the billing system on a regular based. Because of the relatively high cost implementation of smart power 
meters this service is installed on first category clients and on CEZ Shpërndarje substations managing, control all this nodes in the most accurate and correct way [1], [3], [8].

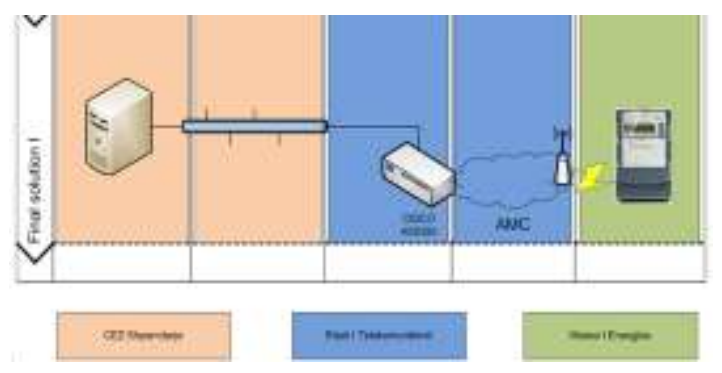

Fig 2. MyAvis System facilitating reading data from Electrometers to the MyAvis and Billing System.

\section{Management of Common Areas and Invoice delivery through Meter-Readers.}

\subsection{Common areas consumption to be treated properly through data cleaning process.}

Common areas have been analyzed and a proposed solution was approved to be implemented under Data Cleaning Project (mid of 2013). The solution proposed at CEZ management time is still valid and need to be implemented even now at OSHEE management [1], [4].

Based on this need I am preparing a policy paper as part of European University research work to be sent to OSHEE for better analyses of this process which seems small but having a big impact at the management of loses process.

Situation at the Billing System: As per the CEZ time period April 2012 till February 2013 the situation on common areas was as following:

- Approx. 8.4k Common Area Electrometer in the Billing System(BS)

- Common Area lights/ Elevators/Water Pump

- The identification was done based on:

Description field / Name of Contract / A flag migrated from old system (KP2 as suggested by MR)

- There was not being marked any new common area Electrometer(EM) since the BS was launched

- Was billed to customers based on imputed "Consumption" incoming from MyAvis (register 3)

- There was no link in Billing System between above listed EM and the customers to be allocated the respective consumption

- $\quad$ Up to April 2012 CEZ Shpërndarje had issued bills for all common areas with 240 ALL service fee \&
TV tariff (until Dec'11). In some cases these invoices have been requested/accepted and paid by the administration of common area (mainly new buildings- no clear mark in BSQF)

- Collective boxes have not been in the system and no link of collective box with Customers.

\section{Situation on the field:}

- Missing functionalities in Myavis System to do proper Common Space Device Management and Distribution of consumption.

- In most of the collective boxes there were EM for the measurement of the common area and there were cases when there were not EM and all can summarized as below:

- Have EM -Have Contracts

- Have EM - Have not Contracts

- Do not have EM- Have contracts

- Do not have EM -Do not have Contract

- In case where the MR can find (calculate) consumption they divided it by no rule to customers of the collective box and sent it through MyAvis in a separate register as a calculated consumption (in $\mathrm{kWh}$ ):

- Since MR has not access to the previous indexes they were keeping previous index in paper at box door.

- There was not an exact procedure for this action and neither any control point for the customers that have been billed and neither for the respective consumption.

The situation is exactly the same now and need to be under analyses and building up a small project to implement such a solution. 4.8 gwh monthly were issued in common areas consumption as part of customer invoice, 0.8 were issued directly to common areas contracts and the entire process was up to the decision of meter readers in the field.

During April-December 2012 there were identified based on their name of contract 6748 Common Area contracts and they have been blocked in printing process. Later have been identified 1682 Common Area Contracts by an old field (KP2) used before BSQF and these cases have not yet been blocked. These cases should be checked in the field and then should be proceeded with blocking of invoicing in Billing System (only in case that the Administrator of Common Area is not paying or taking the responsibility).

From all above we came at the following outputs:

- Not all the energy measured in common area EM was 


\section{A. Dasho, G. Sharko \\ MyAvis and Converge Applications a better Meter-Management System for the Albanian Power Distribution System (OSHEE)}

allocated to customers.

- There were also $0.8 \mathrm{GWh}$ that were directly billed to Common Area Contracts

- On the other hand there were a lot of electrometers that were not in the system which MR were calculating consumption and including to customers invoices.

The entire process was up to the decision of Meter Readers in the field, and $6.3 \mathrm{GWh}$ or $32 \%$ more is the estimation of the energy that can be billed if the common area consumption issue would be solved.

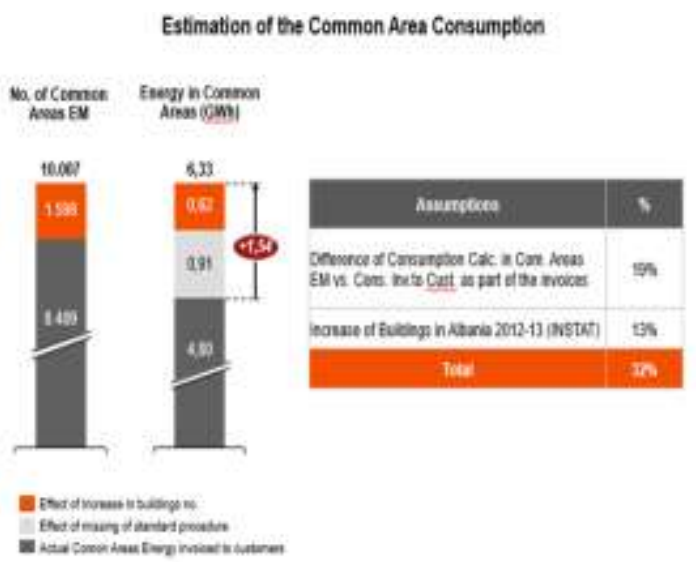

Fig 3. Common Areas Consumtion Estimation.

How the situation had been treated during CEZ time management?

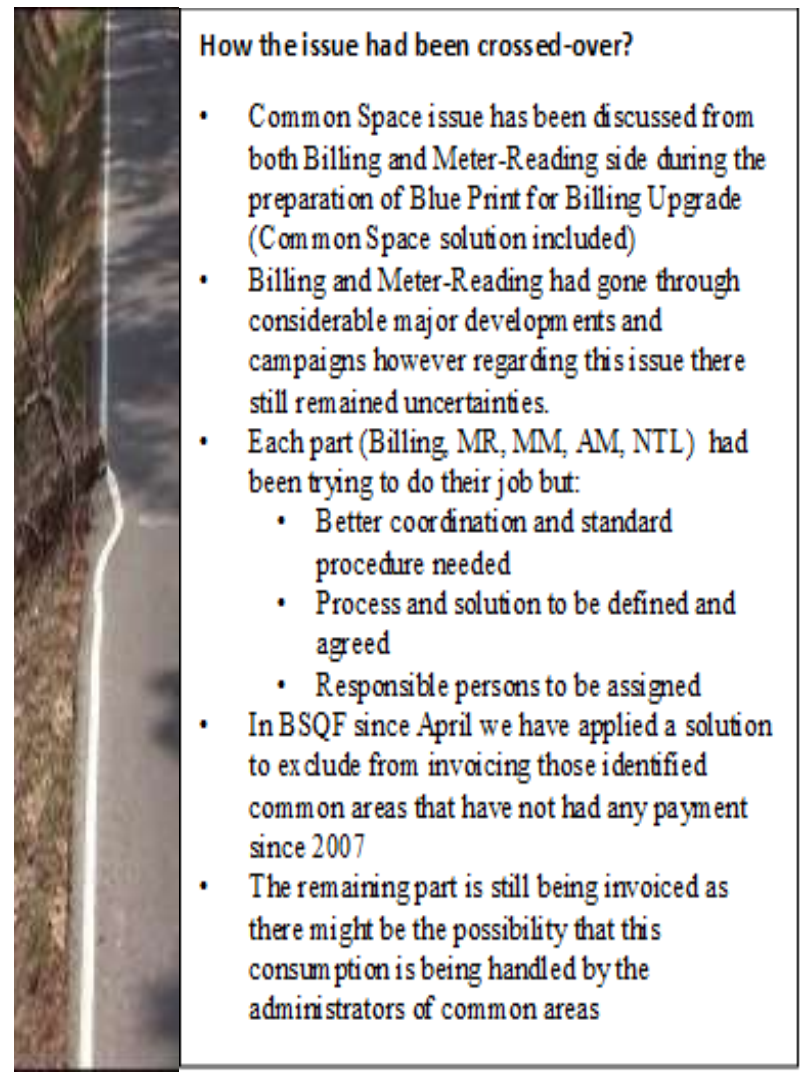

Three steps in which it was more than necessary the cooperation between involved departments would bring a final solutions for actual $\&$ future issue of the common areas.

- Cooperation between all departments is the fundament

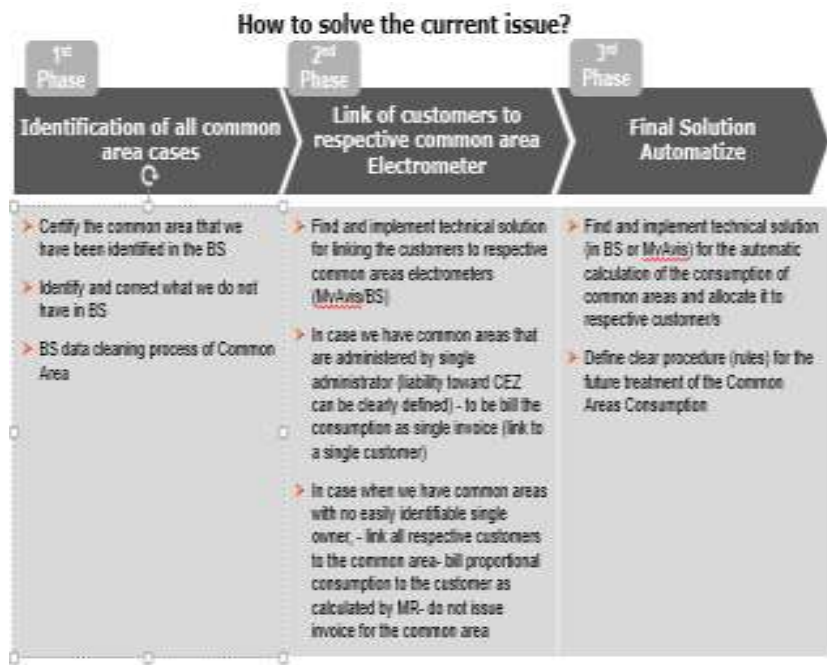

of the success of the implementation of this solution.

- Lack of common area administration is and will also affect the collection of these common area consumption invoices.

\subsection{Invoice delivery through Meter Readers.}

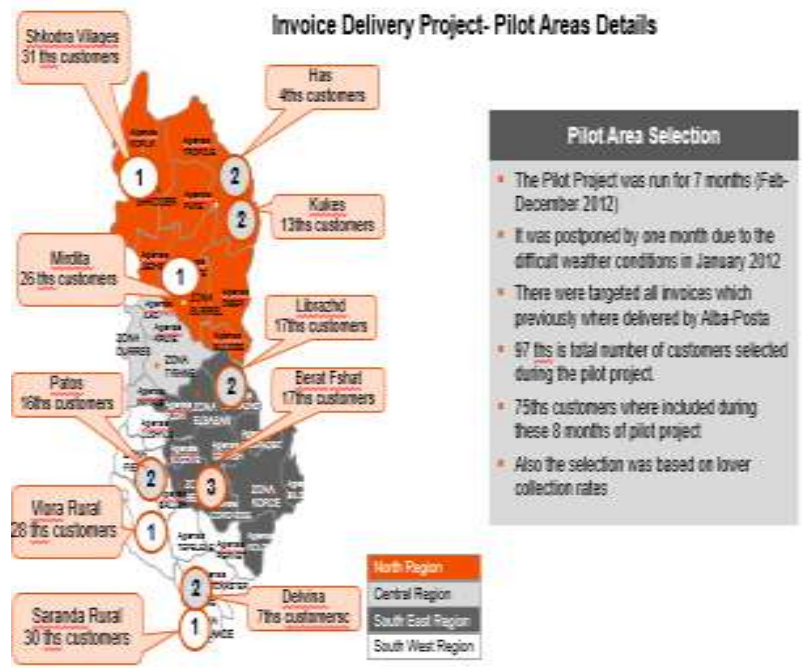

Fig 4. Invoice delivery Project-Pilot areas details

As per this Project the 170000 customers or $14 \%$ of CEZ customer's basis in 10 different areas were selected for the pilot project. In every area where the pilot project was extended it was observed a drastic decrease of 


\section{A. Dasho, G. Sharko \\ MyAvis and Converge Applications a better Meter-Management System for the}

number of invoices printed in customer care centers.

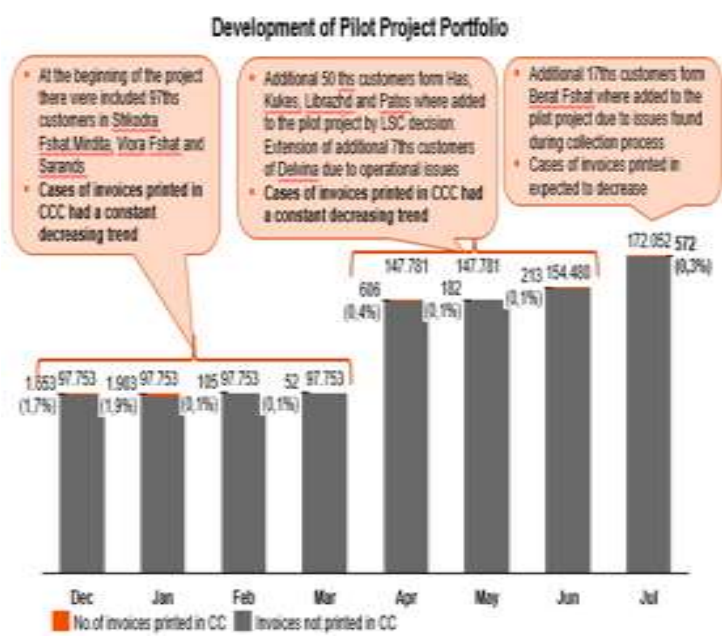

Fig 5. Invoice delivery analyses referring number of invoices printed/not printed anymore in $C C C$.

Despite the restriction to urban and sub-urban areas the phone-call survey reveals a positive impact in the delivery of current invoice through meter-readers.

At the beginning of the project there were included 97ths customers in Shkodra Fshat, Mirdita, Vlora Fshat and Saranda. Cases of invoices printed in Customer Care Centers had a constant decrease trend. Additional 50ths customers from Has, Kukes, Librazhd and Patos were added to the pilot project, extension of additional 7 ths customers of delvina due to operational issues. Even here Cases of invoices printed in Customer Care Centers had a constant decrease trend. At the third part additional 17ths customers from Berat Fshat where added to the pilot project due to the issues found during collection process. Cases of invoices printed in Customer Care Centers in expected to decrease.

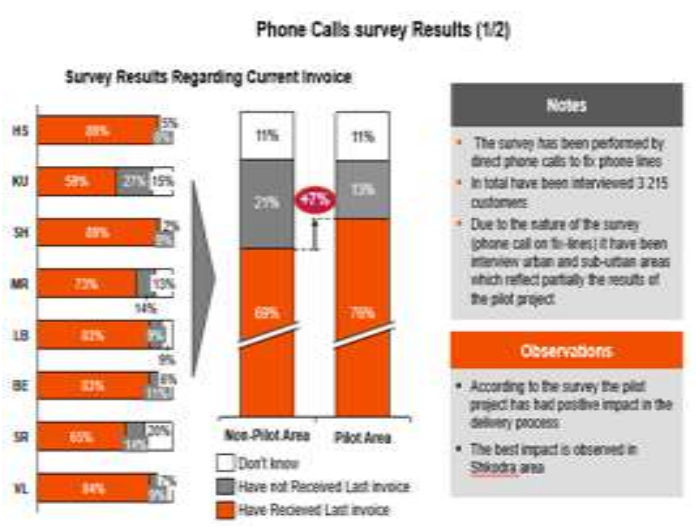

Fig 6. The positive impact in the delivery of current invoice through meter-readers.
The survey has been performed by direct phone calls to fix phone lines. In total have been interviewed 3215 customers. Due to the nature of the survey (phone call on fix lines) it have been interviewed urban and suburban areas which reflect partially the results of the pilot project. According to the survey the pilot project has had positive impact in the delivery process. The best impact has been observed in Shkodra area.

Overall we observe a drastic decrease of invoices printed in CCC and an increasing trend in the collection of "current invoice" during pilot project.
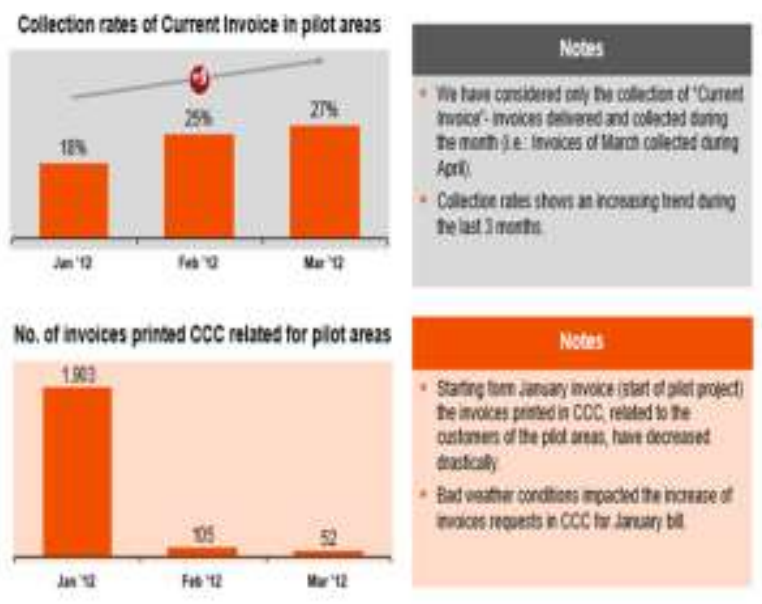

Fig 7 Review of Pilot project impact in Collection Rates and Invoices printed in CCC.

We have observed only the collection of Current Invoice- invoices delivered and collected during the month (i.e. invoices of March collected during April). Collection rate shows an increasing trend during the last 3 months. Starting from January invoice (start of pilot project the invoice printed in CCC, related to the customers of the pilot areas, have decreased drastically. Bad weather conditions impacted the increase of invoices requests in CCC for January bills [1], [5], [7].

\section{Conclusions}

The mobile information system MyAvis is a comprehensive solution for effective and high-quality management of sales and distribution activities in the field.

MyAvis allows companies the effective management of company processes, ensuring of high level of performance, management supervision and required competitive advantages.

It will help to eliminate the ineffective flow of hard copies of documents, introduce an effective model of 
electronically managed work and document flow, and have available fast and precise information about the ongoing fulfilment of working activities in the field.

Regarding the invoice delivery by readers:

- Improvement of the quality of invoices delivery (result re-confirmed by the second survey)

- Improvement of the quality of readings as the invoice delivery serves also as a second control point for the reading process

- Motivation of employees based of the bonus payments (10 Lek/Inv. For Meter Readers and 1 Lek/ Inv for the supporting staff)

- Decrease of invoice in Customer Care

- Positive PR impact due to abovementioned topics

- Increase of overall satisfaction of customer

- Positive impact in collection

Converge system is one of the most is as well a comprehensive solution for effective and high-quality management of sales and distribution activities in the field.

\section{Smart Meters benefits consists of:}

- More accurate bills

- Verify bills in real time - avoid nasty surprises.

- Fewer estimated bills.

- No more meter readers knocking on doors for access.

- No more calls to utilities for appointments with meter readers and inspectors.

\section{Detailed and regular information}

- Near real-time interval usage and billing information.

- Monthly billing.

- Ability to switch to 'best price fit' retailer.

- Choice of retailer tariffs.

- Discretionary modification to electricity use.

- Communication about type of service received (for example, outages and quality).

\section{Better service}

- Reduced number of calls to utilities call centres.

- Faster reconnections after power outages.

- Greater understanding by consumers of the quality of the power supply (power fluctuations).

\section{Environmentally save}

- Better management of energy usage.

- Implementation of in-home energy conservation scheme that suits the household.

- Realisation that a consumer behaviour can change the utility's behaviour.

\section{References}

Official web page of CEZ Group Prague/ CEZ Albania/ Kvados Group/Landis and Gyr Company

[1] http://www.cez.cz,http://www.cez.al, http://www.cez.ro,http://www.cez.bg, http://www.oshee.al;

[2] http://www.kvados.cz

[3] http://www.landisgyr.com

[4] "Smart Meters and Smart Meter Systems, A Metering Industry Perspective"; An EEI-AEIC-UTC White Paper; February 2011.

[5] Francis Buttle (2009), Customer Relationship Management, Concepts and Technologies, SE, PP 409-412.

[6] Rial, A., Danezis, G.: Privacy-Preserving Smart Metering. In: Workshop on Privacy in the Electronic Society (2011).

[7] "Wireless Transmissions: An Examination of OpenWay Smart Meter Transmissions in a 24 hour Duty Cycle"; Itron Inc.; 2011.

[8] "Evaluation of Advanced Meter System Deployment in Texas -Meter Accuracy Assessment"; Navigant Consulting (PI) LLC; July 30, 2010.

[9] M.S.Jaganmohan; K. Manikandan "Challenges in Smart Meter Design" Power system protection and automation conference, December 2010, New Delhi, India. 